\title{
MEASURING COSTS AND OUTCOMES \\ OF TELE-INTERVENTION WHEN SERVING FAMILIES OF CHILDREN WHO ARE DEAF/HARD-OF-HEARING
}

\author{
KRISTINA M. BLAiser, PHD, CCC-SLP, ${ }^{1}$ DiAnE BEHL, MED, ${ }^{2}$ \\ CATHERine CAllow-Heusser, PhD, ${ }^{2}$ Karl R. White, PhD ${ }^{2}$ \\ DePARTMENT OF COMMUNiCATIVE Disorders and DeAF EDUCATION, COlLEGE OF EDUCATION \\ AND HUMAN SERVICES, UTAH STATE UNIVERSITY, LOGAN, UT \\ 2 NATIONAl CENTER FOR HEARING ASSESSMENT AND MANAGEMENT, UTAH STATE UNIVERSiTy, \\ LOGAN, UT
}

\section{ABSTRACT}

Background: Optimal outcomes for children who are deaf/hard-of-hearing (DHH) depend on access to high quality, specialized early intervention services. Tele-intervention (TI), the delivery of early intervention services via telehealth technology, has the potential to meet this need in a cost-effective manner.

Method: Twenty-seven families of infants and toddlers with varying degrees of hearing loss participated in a randomized study, receiving their services primarily through TI or via traditional in-person home visits. Pre- and post-test measures of child outcomes, family and provider satisfaction, and costs were collected.

Results: The TI group scored statistically significantly higher on the expressive language measure than the in-person group ( $p=.03$ ). A measure of home visit quality revealed that the TI group scored statistically significantly better on the Parent Engagement subscale of the Home Visit Rating Scales-Adapted \& Extended (HOVRS-A+; Roggman et al., 2012). Cost savings associated with providing services via TI increased as the intensity of service delivery increased. Although most providers and families were positive about $\mathrm{TI}$, there was great variability in their perceptions.

Conclusions: Tele-intervention is a promising cost-effective method for delivering high quality early intervention services to families of children who are $\mathrm{DHH}$.

Keywords: Deaf/hard-of-hearing, tele-intervention, early intervention

Approximately 3 children per 1,000 are born with permanent hearing loss, making this the most frequent congenital condition in the United States (White, 2007). When not detected and treated early, children who are deaf/hard-of-hearing (DHH) experience speech and language delays that contribute to problems with cognitive, language, academic, and social development (White, Forsman, Eichwald, \& Muñoz , 2010). Twenty years ago, children born with hearing loss were typically not identified until they were 2 to 3 years old (Towards Equality, 1988; White, 2007). Today universal newborn hearing screening, coupled with advances in hearing technologies (e.g., digital hearing aids, cochlear implants) and early intervention programs, enables most children who are $\mathrm{DHH}$ to achieve on par with their hearing peers (Koehlinger, Owen Van Horne, \& Moeller, 2013). Such positive outcomes are most likely, however, if children are identified within the first months after birth and receive appropriate medical, audiological, and educational services (McCann et al., 2009).

Although the benefits of early intervention for children who are DHH have been demonstrated, many of these children are still not receiving appropriate services
(Center for Disease Control and Prevention (CDC), 2013). In fact, a letter to all early intervention state programs from the US Departments of Education and Health and Human Services noted a "growing national crisis in the provision of essential early intervention and health care services for infants and toddlers with hearing loss" (Hager \& Giannini, personal communication, July 21, 2006). The primary reasons such inadequate services occur include the following (CDC, 2013; White, 2007):

- There is a severe shortage of professionals who are trained and knowledgeable about current methods for effectively educating children who are $\mathrm{DHH}$;

- Childhood hearing loss is a relatively low incidence condition, which means that children who are DHH may live a great distance from the specialized services they need;

- The lack of a "critical mass" of children who are DHH in a given area, particularly rural areas, makes it difficult to find appropriately trained early intervention providers; and

- Even in densely populated areas, accessing professionals who are knowledgeable and trained can be challenging given the geographic dispersion of children who are $\mathrm{DHH}$, the shortage of adequately trained professionals, and scheduling or transportation constraints. 
Because of recent improvements in information and communication technology, telehealth has the potential of addressing these challenges. Tele-intervention (TI), also referred to as virtual home visits (VHV), has the potential to ensure families of children with special needs - including those who are $\mathrm{DHH}$ - receive family-centered, routines-based early intervention services in the natural environment.

Over a decade ago, the American Speech-LanguageHearing Association (Rosenfeld, 2002) reported that $11 \%$ of survey respondents used telepractice to provide services. More recently, a survey of Early Hearing Detection and Intervention (EHDI) systems conducted by the National Center for Hearing Assessment and Management (NCHAM, 2010) found that of 48 US states and territories, $42 \%$ had telehealth or telepractice efforts under way or planned, primarily for early intervention and communication-related therapies. To advance this effort, the American Speech-Language-Hearing Association (ASHA, 2005a; 2005b) issued the statement, "telepractice is an appropriate model of service delivery for the profession of speech-language pathology. Telepractice may be used to overcome barriers of access to services caused by distance, unavailability of specialists ... and impaired mobility (p. 1)."

Unfortunately, few rigorous studies of the efficacy or cost-effectiveness of services provided through two-way conferencing systems have been conducted (Hjelm, 2005; Mashima \& Doarn, 2008; Scott et al., 2007; Wootton, 2001). A recent monograph provides the most current published information about the use of TI to support early intervention to infants and toddlers who are $\mathrm{DHH}$ (Blaiser, Edwards, Behl, \& Muñoz, 2012; Behl, Houston, \& Stredler-Brown, 2012). Similar to previous literature on this topic, articles in the monograph describe applications of this technology and draw attention to the need for better evidence, with very little evidence being reported.

In response to the need for higher quality evidence, a study was designed to compare the costs and effects of TI compared to traditional in-person early intervention service delivery. The study engaged providers and families from a state-wide early intervention program for infants and toddlers who were $\mathrm{DHH}$.

\section{METHOD}

A randomized control trial was employed, including the collection of child, family, provider, and cost data. Pretest data were collected prior to the six-month intervention period, followed by post-test data collection.

\section{PARTICIPANTS}

Families enrolled in the Utah Schools for the Deaf and Blind (USDB) Parent Infant Program (PIP) were invited to participate in this study. Thirty-five families whose primary language was English were randomly assigned to Tl or traditional in-person intervention groups. Children in each group were matched on age, degree of hearing loss, geographic location (i.e., rural or urban), and communication modality (American Sign Language (ASL) or Listening and Spoken Language (LSL). Of the initial 38 families, both pre-and post-test data were collected for 27 families and included in subsequent analyses. Of the eight families who were randomly assigned but not included in the data reported here, three families moved out of the service area before the study was completed, one withdrew from the study because they preferred to not receive $\mathrm{TI}$ services, and four did not have child pretest data. Additionally, one family included in the analysis was randomly assigned to the TI group but refused TI services after the first visit though they continued to receive inperson visits. Because of the "intent to treat" with TI services, their data were included with the TI group in the analyses. As shown in Table 1, the groups were well matched on these key variables.

Table 1. Family and Child Characteristics at Beginning of Study

\begin{tabular}{lll}
\hline Characteristic & TI Group & In-Person Group \\
\hline Final Sample Size & 13 & 14 \\
\hline $\begin{array}{l}\text { Average child age } \\
\text { in months (range) }\end{array}$ & $18(10-28)$ & $19(2-33)$ \\
\hline Male/Female & $6 / 7$ & $4 / 10$ \\
\hline $\begin{array}{l}\text { Additional Disabilities } \\
\text { (2 Multiple, }\end{array}$ & $\begin{array}{l}1 \text { Multiple, } \\
1 \text { Down syndrome }\end{array}$ \\
\hline $\begin{array}{l}\text { Cochlear Implants } \\
\begin{array}{l}\text { Communication choice: } \\
\text { ASL/LSL/Undecided }\end{array}\end{array}$ & 2 & 2 \\
\hline
\end{tabular}


intervention services with each provider serving children in both groups ( $\mathrm{TI}$ and in-person). Immediately prior to the start of the study period, each provider participated in a 2-hour training covering use of equipment, preparation procedures, and typical session routines. Video examples of TI sessions were viewed. Over the first few weeks of the study, providers were contacted regularly to monitor challenges with the equipment, connectivity, or other service delivery issues. No directed training pertaining to the use of coaching or other best practices was provided beyond what the providers received within their employment setting.

\section{INTERVENTION}

During the six-month period from January through June 2013, families in each of the groups were scheduled to receive PIP services in accordance with their Individualized Family Service Plan (IFSP). The mean number of prescribed monthly sessions was two visits per month. Children in the TI group received one of these visits via two-way video conferencing. A second visit with the same provider was an in-person home visit as required by state Part $C$ policies.

Families in the TI group and PIP providers were provided with laptops preprogrammed with Voice over Internet Protocol (VoIP) software with additional software and procedures to ensure compliance with the Health Insurance Portability and Accountability Act (HIPAA). Connectivity speeds for families and providers were assessed prior to intervention. Five of the families and one provider in the study had no Internet access or insufficient bandwidth, and a variety of methods were used to ensure adequate connectivity. Midway through the study, all families who had insufficient bandwidth were upgraded to a minimum of $1.5 \mathrm{Mbps}$, with the costs covered by the researchers.

\section{INSTRUMENTATION}

A variety of measures were used to assess the children's developmental outcomes, user perceptions, quality of the intervention, and costs.

\section{CHILD OUTCOMES}

The amount of progress made by each child in receptive and expressive language was measured using the SKIHI Language Development Scale (LDS; Hope Publishing, 2004). This criterion-referenced scale is developmentally ordered and contains a list of communication and language skills in varying intervals for different ages. Each age interval is represented by enough observable receptive and expressive language skills to obtain a good profile of a child's language ability. Reliability and validity for the LDS scales were established in previous studies, reflecting strong inter-rater reliability, test-retest reliability, and internal consistency (Strong, Clark, Barringer, Walden, \& Williams, 1992; Tonelson, 1980).

\section{CAREGIVER AND PROVIDER PERCEPTIONS}

Researcher-developed self-report surveys administered to families in the TI group as well as to providers were used as pre- and post-test measures. Surveys included Likert-type items as well as open-ended questions pertaining to perceptions about the benefits and challenges of using $\mathrm{Tl}$ as well as their own comfort with the use of $\mathrm{TI}$.

\section{HOME VISIT QUALITY}

The quality of intervention and interpersonal dynamics of the intervention sessions were rated using the Home Visit Rating Scales-Adapted \& Extended (HOVRS-A+; Roggman et al., 2012), which is designed to measure excellence based on evidence-based practices for home visits with families of children ages birth to 24 months. The scales measure four indicators of home visit quality based on the home visitor's responsiveness to family, relationship with family, facilitation of the parent-child interaction, and non-intrusiveness and collaboration. Three additional scales provide indicators of home visitor effectiveness during the home visit: parent-child interaction, parent engagement, and child engagement. Strong internal consistency is reported (Vogel et al., 2011). Video recordings of four families in the TI group and four families in the comparison group with matched providers were independently coded by one of the authors of the HOVRS-A+.

\section{COSTS}

The costs of providing services ( $\mathrm{Tl}$ and in-person) were measured using a researcher-developed cost form that included service delivery time; travel time and expenses; and equipment and Internet service costs. Additional technology costs and technical support time were also included. Providers completed cost forms every other week during four months of the study. 


\section{RESULTS}

The following results are based on pre-post measures following a six-month intervention period.

\section{CHILD OUTCOMES}

As shown in Figure 1, mean scores in receptive and expressive language skills for children in the TI group were higher than children in the comparison group when covaried on pretest scores and chronological age. Differences in favor of the TI group were statistically significant for expressive language $(p=.03$, standardized mean difference effect size, or SMDES $=.40$ ), but not for receptive language $(p=.22$, SMDES $=.23)$. Effect sizes in favor of the TI group for both expressive and receptive language differences are noteworthy.

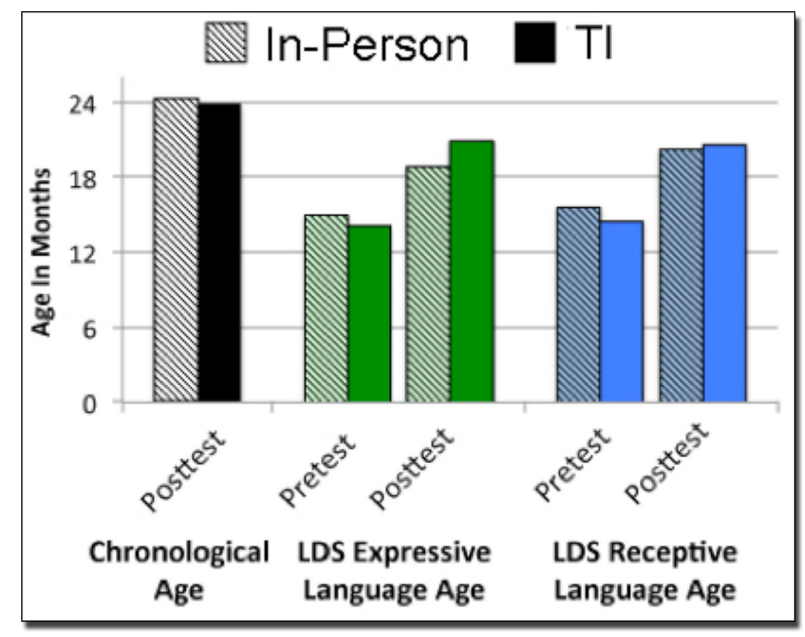

Figure 1. Pre- and post-test differences in LDS scores for In-person and TI groups.

\section{CAREGIVER AND PROVIDER PERCEPTIONS}

After about three months, caregivers in the TI group rated their satisfaction a 6.9 on a 10-point scale with 10 being highly satisfied. An additional self-report survey was administered to providers at postest. Post-test data revealed that, compared to the onset of the study, caregivers felt that $\mathrm{TI}$ services were helpful in reducing the number of visits missed due to illness or bad weather and did not interfere with their relationships and interactions with providers. The most significant benefit reported by families was that $\mathrm{TI}$ facilitated family engagement during sessions and put the family "in the driver's seat." The biggest challenge and most frustrating aspect was connectivity. Caregivers reported that they learned how to help their child more through $\mathrm{TI}$ than in traditional in-person visits, and that they were more involved in the TI sessions. In addition to difficulties with technology, caregivers reported challenges with keeping their child engaged and feeling that the visit was less personal than the in-person visit.

A post-test self-report survey was administered to providers to obtain their perspectives on the strengths and challenges of TI. Post-test data revealed that, compared to the onset of the study, providers used video conferencing technology more in their personal life, felt more comfortable with coaching, and shifted the focus of interactions in sessions from parent-visitor interactions to parent-child interactions. Providers continued to have reservations about personal contact with families in a $\mathrm{TI}$ model and providing therapy that supported natural environments. Based on qualitative responses, providers appreciated the benefits of reduced travel time in serving families who live far away as well as avoiding exposure to an ill family member.

\section{HOME VISIT QUALITY}

Recordings of sessions independently scored by an author of the HOVRS-A+ indicated that average ratings favor the TI group. Group means, standardized mean difference effect sizes (SMDES), and the results of statistical tests of differences between groups are shown in Table 2. All differences favor the TI group except child engagement, though differences in child engagement are quite small as shown in Figure 2. Additionally, the group difference for Parent Engagement during Home Visit was statistically significant $(\mathrm{p}<.05)$, indicating that parents in the $\mathrm{TI}$ group were more engaged during the $\mathrm{TI}$ session than parents in the comparison group during the home visit. 
Table 2. Statistics Showing HOVRS Differences between TI and Comparison Groups

\begin{tabular}{|c|c|c|c|c|c|}
\hline HOVRS Scale & $\begin{array}{l}\text { Mean: } \\
\text { TI }\end{array}$ & $\begin{array}{l}\text { Mean: } \\
\text { Comparison }\end{array}$ & $\begin{array}{l}\text { Standard } \\
\text { Error }\end{array}$ & SMDES & p-value \\
\hline $\begin{array}{l}\text { Home Visitor Responsiveness } \\
\text { to Family (HVRESP) }\end{array}$ & 4.177 & 4.073 & 0.459 & 0.2 & 0.645 \\
\hline $\begin{array}{l}\text { Home Visitor Relationship } \\
\text { with Family (HVFamRel) }\end{array}$ & 5.485 & 4.765 & 0.438 & 1.6 & 0.509 \\
\hline $\begin{array}{l}\text { Home Visitor Facilitation } \\
\text { of Parent-Child Interaction } \\
\text { (HVFacPCint) }\end{array}$ & 4.966 & 4.034 & 0.446 & 2.1 & 0.332 \\
\hline $\begin{array}{l}\text { Home Visitor } \\
\text { Non-Intrusiveness \& } \\
\text { Collaboration (HVCollab) }\end{array}$ & 4.058 & 3.192 & 0.656 & 1.3 & 0.654 \\
\hline $\begin{array}{l}\text { Parent-Child Interaction } \\
\text { during Home Visit (PCInteract) }\end{array}$ & 5.875 & 4.875 & 0.382 & 2.6 & 0.160 \\
\hline $\begin{array}{l}\text { Parent Engagement during } \\
\text { Home Visit (PEngage) }\end{array}$ & 5.599 & 4.401 & 0.200 & 6.0 & 0.017 \\
\hline $\begin{array}{l}\text { Child Engagement during } \\
\text { Home Visit (CEngage) }\end{array}$ & 5.186 & 5.314 & 0.493 & -0.3 & 0.174 \\
\hline
\end{tabular}

for the two groups (20 and 17 minutes for the inperson group, and 19 and 22 minutes for the TI group, respectively). Consequently, the cost of salaries and wages for providers to prepare, deliver, and document services was assumed to be the same for children in both groups.

For each child in the in-person group, providers drove an average of 22 miles in each direction, requiring an extra 60 minutes of their time (valued at \$55 per hour for salary and benefits) and a cost of \$22 for driving expenses (valued at $\$ 0.50$ per mile). Thus, each home visit cost an additional $\$ 77$ in provider time and expenses as compared to a TI visit. Additional costs for children in the TI group included enhanced Internet service and software licensing fees $(\$ 60 /$ month) for the provider, and for each family a computer, microphone,

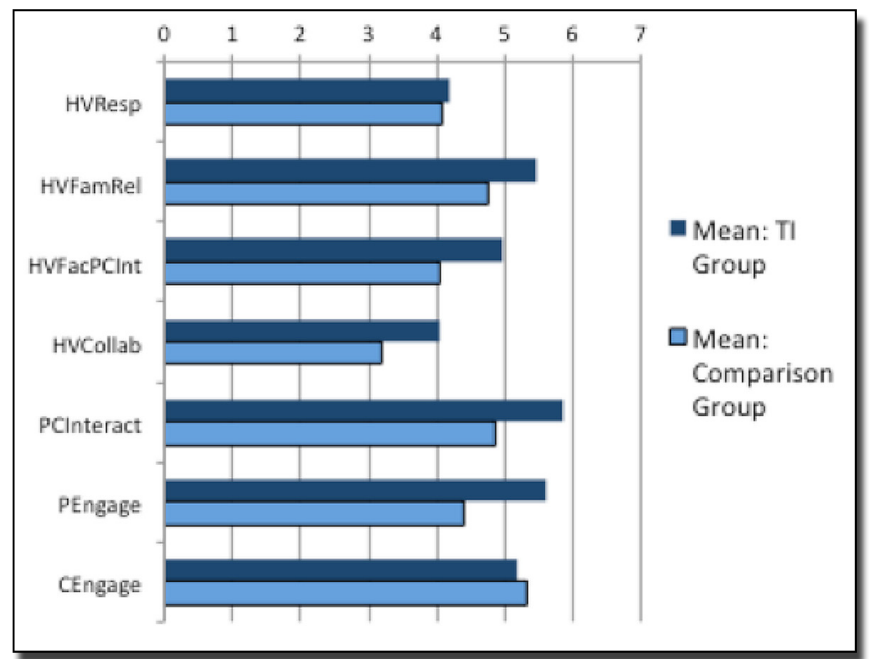

Figure 2. HOVRS differences between TI and comparison groups.

\section{COSTS}

The amount of time providing services to children was similar for both groups (59 minutes for in-person and 51 minutes for $\mathrm{TI}$ ). Time spent preparing for visits and documentation/record keeping was almost identical camera and monitor (one time cost of $\$ 1,000$ ), enhanced Internet service and software costs ( $\$ 60$ per month per family), and their share of the technology specialist who was responsible for system set up, training parents and providers in using the equipment, and ongoing support (\$50 per month per family).

Using these figures, the estimated cost of providing services for a two-year period to 15 families (assumed to be the average "caseload" for a single provider) is shown in Figure 3. As seen in this figure, if every child received an average of only one visit per month, in-person services are less expensive than TI services. However, if more frequent services were provided, TI services have a growing financial advantage. If 3-4 visits were provided to each child each month (similar to what is reported in an ongoing study being conducted by the National Institutes of Health (Outcomes of Children with Hearing Loss, 2013), the cost savings for providing services to 15 families using $\mathrm{Tl}$ instead of in-person services would be $\$ 56,280$ to $\$ 86,970$ over a 24 month period. Such cost savings, taken together with the evidence that children in the TI group (as described herein) make as good or better progress in receptive and expressive language, suggests that $\mathrm{TI}$ should be seriously considered as a way of delivering services to all 0-3 year old children who are $\mathrm{DHH}$. 


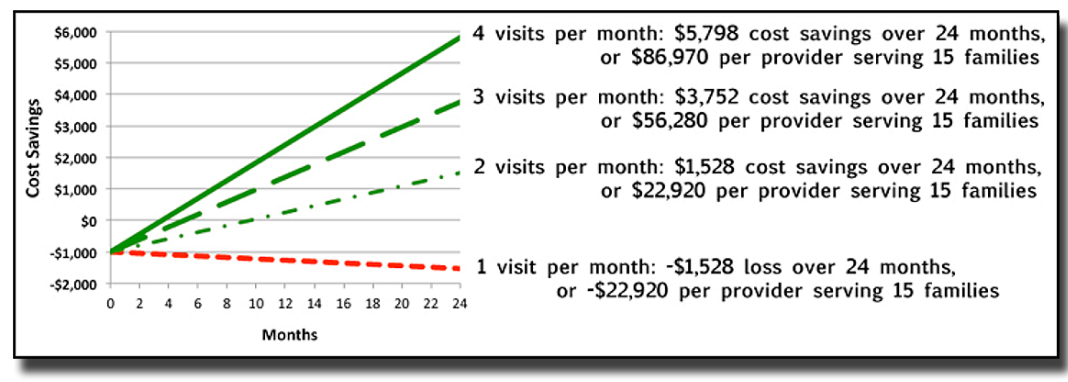

Figure 3. Cost savings for TI when compared to In-person home visit.

\section{DISCUSSION}

This randomized controlled study contributes to our current knowledge about the costs and effects of TI when compared to in-person home visits. Though the sample sizes in this study were relatively small and the duration of the study was short, the resulting evidence indicates that children of families who receive TI services (as described herein) make more developmental progress in language skills than children receiving services through in-person early intervention home visits. Both families and providers indicated that a benefit of TI was the convenience of not leaving home or office to travel across town in traffic or bad weather, and when children or other family members were sick.

This study's use of a comprehensive measure of the quality of intervention is also a significant contribution to the investigation of TI. Best practices in early intervention encourage providers to facilitate and "coach" families in interactions with their children. As shown above, Tl resulted in increased parent-child engagement, as opposed to child-provider interactions. These results could be due to the nature of the delivery system itself whereby the providers interact more with caregivers than children during TI-based early intervention sessions. As a result, TI providers facilitate parent-child interactions and ultimately improve the caregiver's ability to nurture their child's development, through the use of TI. Though the sample included in this analysis was small, it accounted for provider differences by including families in each group for each provider. However, further research with a larger sample size is needed to replicate these results. Additionally, monitoring changes in the quality of home visits over time would be a valuable contribution.

Provider and caregiver perceptions varied greatly in terms of support for TI. Two families withdrew from the study, preferring not to use the TI service delivery model. The reasons given suggest that the families felt that the additional effort associated with learning a new technology was not desirable or feasible for them at the time. Technology challenges faced by many of the partcipants during the first few months of the study also influenced provider and caregiver satisfaction with TI.
Both provider and caregiver perceptions of $\mathrm{TI}$ improved dramatically when connectivity issues were solved. Programs interested in implementing $\mathrm{TI}$ services need to consider and account for cost and time related to making sure that providers and families have sufficient bandwidth. One of the most salient results of this study was the value of setting the goal of $1.5 \mathrm{Mbps}$ upload and download speeds to ensure adequate communication quality. This means that families living in remote areas without access to sufficient bandwidth are still likely to face challenges in accessing important services.

The cost analysis provided evidence that, given an average of three to four intervention sessions per month, the cost savings from TI over time could be substantial. Given the financial challenges faced by many early intervention programs as the demand for their services grow, the results of this study suggest that $\mathrm{Tl}$ is a viable method to ensure the needed intensity of services can be provided.

There are other potential benefits of $\mathrm{TI}$ that were not targeted for measurement, yet are worth noting. For example, one family preparing for a cochlear implant surgery was able to receive additional consultation via TI from an audiologist about device choice and have this consultation held at a time when the father could be present. This would probably not have been possible if the audiologist would have been required to make an inperson visit. Such anecdotes reflecting interdisciplinary teaming point to another important outcome to be measured in future studies.

This study has limitations that must be considered in the interpretation of the results. First, although the sample size was larger than most other TI studies with children who are DHH reported in the literature, studies with even larger samples are needed. Second, the short duration of the intervention period and the limited intensity of service delivery may have reduced the documentation of potential outcomes, particularly given the initial connectivity challenges faced by some of the TI families. Additional research using standardized measures of child development versus criterion-referenced tools also would strengthen the evidence base. Finally, there are additional factors to be investigated in regard to the role of TI. For example, the degree of training and skill set required for optimal TI implementation is an area of further study.

In conclusion, this study demonstrated that $\mathrm{TI}$ has the potential to ensure that all families who have children who are $\mathrm{DHH}$, regardless of their geographic location, have access to high quality, specialized early intervention. TI not only increases a family's access to providers, but, due to the nature of the TI interactions, also has the potential to be more successful in supporting the use of "coaching" families in their natural environments. This message is important to share with payors of early intervention services, who may be skeptical of TI (Cason, Behl, \& 
Ringwalt, 2012). It is likely the reality of limited budgetary resources to meet the growing demand of services will lead to the acceptance of TI. It behooves TI supporters to be prepared with evidence to support this direction.

\section{REFERENCES}

1. American Speech-Language-Hearing Association. (2005a). Audiologists providing clinical services via telepractice. [Position statement].

2. American Speech-Language-Hearing Association. (2005b). Speech-language pathologists providing clinical services via telepractice. [Position statement].

3. Behl, D., Houston, K. T., \& Stredler-Brown, A. (2012). The value of a learning community to support telepractice for infants and toddlers with hearing loss. Volta Review, 112, 313-296.

4. Blaiser, K., Edwards, M., Behl, D., \& Muñoz, K. (2012). Tele-intervention services at Sound Beginnings at Utah State University. Volta Review, 112, 365-372.

5. Cason, J., Behl, D., \& Ringwalt, S. (2012). Overview of states' use of telehealth for the delivery of early intervention (IDEA Part C) services. International Journal of Telerehabilitation, 4, 39-46. doi: 10.5195/ijt.2012.6105

6. Center for Disease Control and Prevention (CDC). (2013). Summary of national CDC $2011 \mathrm{EHDI}$ data. Retrieved from http://www.cdc.gov/ncbddd/hearingloss/ehdidata2011.html

7. Hjelm, N. M. (2005). Benefits and drawbacks of telemedicine. Journal of Telemedicine and Telecare, 11, 60-70.

8. Hope Publishers. (2004). Language Development Scale. Retrieved from http://www.hopepubl.com

9. Koehlinger, K., Owen Van Horne, A. J., \& Moeller, M. P. (2013). Grammatical outcomes of 3 \& 6 year old children with mild to severe hearing loss. Journal of SpeechLanguage-Hearing Research. Manuscript in preparation.

10. Mashima, M. \& Doarn, C. (2008). Overview of telehealth activities in speech-language pathology. Telemedicine and e-Health, 14, 1101-1117.

11. McCann, D.C., Worsfold, S., Law, C.M., Mullee, M., Petou, S., Stevenson, J.,... Kennedy, C.R. (2009). Reading and communication skills after universal newborn screening for permanent childhood hearing impairment. Archives of Disease in Childhood, 94, 293297.

12. National Center for Hearing Assessment and Management. (2010). NCHAM 2010 Telehealth Survey. Retrieved from http://www.infanthearing.org/telehealth/ docs/Telehealth\%20Survey\%20Summary.pdf

13. Outcomes of children with hearing loss: A study of children ages birth to six. 2013. Funded by the National Institute of Deafness and Other Communicative Disorders grant \# DC009560. Retrieved from http://www. uiowa. edu/ ochl.

14. Roggman, L.A., Cook, G.A., Innocenti, M.S., Jump Norman, V.K., Christiansen, K., Boyce, L. K., ... Hallgren, K. (2012). Home Visit Rating Scales-Adapted and Extended (HOVRS-A+). Baltimore, MD: Brooks Publishing.

15. Rosenfeld, M. (2002, October). Report on the ASHA speech-language pathology health care survey. Rockville, MD: American Speech-Language-Hearing Association.

16. Scott, R.E., McCarthy, F.G., Jennett, P.A., Perverseff, T., Lorenzetti, D., Saeed, A., ... Yeo, M. (2007). Telehealth outcomes: A synthesis of the literature and recommendations for outcome indicators. Journal of Telemedicine and Telecare, 13(Suppl)2, 1-38. 
17. Strong, C. J., Clark, T. C., Barringer, D. G., Walden, B. E., \& Williams, S. A. (1992). SKI-HI home-based programming for children with hearing impairments: Demographics, child identification, and program effectiveness, 1979-1991. A three-year study conducted at the SKI-HI Institute. Logan, UT: SKI-HI Institute, Utah State University.

18. Tonelson, S. W. (1980). A validation study of the SKI-HI language development scale (Unpublished doctoral dissertation). University of Virginia, Charlottesville, VA. (AAT 8102583)

19. Toward Equality. (1988). A report to the Congress of the United States: Toward equality- Commission on Education of the Deaf. Washington, DC: U.S. Government Printing Office.

20. Vogel, C.A., Boller, K., Xue, Y., Blair, R., Aikens, N., Burwick, A., ... Stein, J.. (2011). Learning as we go: A first snapshot of Early Head Start programs, staff, families, and children. Report No. 2011-7. Washington, DC: Office of Planning, Research, and Evaluation, Administration for Children and Families, U.S. Department of Health and Human Services.

21. White, K. R., (2007). Early intervention for children with permanent hearing loss: Finishing the EHDI revolution. The Volta Review, 106, 237-258.

22. White K. R., Forsman, I., Eichwald, J., \& Muñoz, K. (2010). The evolution of early hearing detection and intervention programs in the United States. Seminars in Perinatology, 34, 170-179.

23. Wootton, R. (2001). Recent advances: Telemedicine. British Medical Journal, 323, 557-560. 